\title{
Preparation of Activated Carbon for the Removal of Pb (II) from Aqueous Solutions
}

\author{
Rajeshwar Man Shrestha ${ }^{1^{*}}$, Raja Ram Pradhananga ${ }^{2}$, Margit Varga $^{3}$, Imre Varga ${ }^{3}$ \\ ${ }^{1}$ Department of Engineering Science and Humanities, Institute of Engineering, Tribhuvan University, \\ Nepal, ${ }^{2}$ Central Department of Chemistry, Tribhuvan University, Nepal, ${ }^{3}$ Department of Analytical \\ Chemistry, Eotvos Lorand University, Budapest, Hungary; Email: r_shrestha4444@hotmail.com
}

\begin{abstract}
The present study deals with the use of activated carbons prepared from Lapsi seed stone as adsorbents for the removal of $\mathrm{Pb}$ (II) ions from aqueous solution. Two series of carbon have been prepared from Lapsi seed stones by treating with conc. $\mathrm{H}_{2} \mathrm{SO}_{4}$ and a mixture of $\mathrm{H}_{2} \mathrm{SO}_{4}$ and $\mathrm{HNO}_{3}$ in the ratio of 1:1 by weight for removal of metal ions. Chemical characterization of the resultant activated carbon was studied by Fourier Transform Infrared Spectroscopy and Boehm titration which revealed the presence of oxygen containing surface functional groups like carboxylic, lactonic, phenolic in the carbons. The effect of $\mathrm{pH}$ and initial metal ion concentration on the adsorption was studied in a batch process mode. The optimum $\mathrm{pH}$ for lead adsorption is found to be equal to 5.The adsorption data were better fitted with the Langmuir equations than Freundlich adsorption equation to describe the equilibrium isotherms. The maximum adsorption capacity of $\mathrm{Pb}$ (II) on the resultant activated carbons was $277.8 \mathrm{mg} \mathrm{g}^{-1}$ with $\mathrm{H}_{2} \mathrm{SO}_{4}$ and $423.7 \mathrm{mg} \mathrm{g}^{-1}$ with a mixture of $\mathrm{H}_{2} \mathrm{SO}_{4}$ and $\mathrm{HNO}_{3}$. The waste material used in the preparation of the activated carbons is inexpensive and readily available. Hence the carbons prepared from Lapsi seed stones can act as potential low cost adsorbents for the removal of Pb (II) from water.
\end{abstract}

Keywords: Adsorption, Lapsi seed stones, Carbon, Adsorption isotherms, Lead

\section{Introduction}

Due to toxicity and non -biodegradability even at lower concentrations heavy metals like lead, cadmium , nickel, chromium etc. are hazardous to the environment ${ }^{1}$. Lead is released into natural water from textile dyeing, ceramic and glass industries, petroleum refining, battery manufacture and mining operations ${ }^{2}$. In drinking water lead contamination occurs due to the corrosion and leaching of lead pipes and $\mathrm{Pb} / \mathrm{Sn}$ solder joints associated with copper service lines used in household plumbing ${ }^{3}$. Lead is a highly toxic and cumulative poison, accumulates mainly in bones, brain, kidney and muscles. Lead poisoning in human causes severe damage to kidney, nervous and reproductive systems, liver and brain ${ }^{4}$. The permissible level of lead in drinking water and surface water intended for drinking as set by EU, EPA and WHO are $0.01,0.05$ and $0.01 \mathrm{mg} \mathrm{L}^{-1}$ respectively. Therefore, a very low concentration of lead in water is very toxic. The removal of such a heavy metal from contaminated water bodies has been attempted by several scientists employing a wide variety of techniques including chemical precipitation, chemical oxidation or reduction, filtration, ion exchange, electrochemical treatment, membrane filtration, reverse osmosis and adsorption. However, most of these methods have considerable disadvantages including incomplete metal removal, high capital, operational cost and the disposal of residual metal sludge which are not suitable for small scale industries ${ }^{5}$.

\section{${ }^{*}$ Corresponding author}


Among various methods, the adsorption process has been used exclusively in water treatment and many studies have been carried out to find inexpensive and chemico-physically feasible adsorbent. Many reports have appeared on the development of low cost activated carbon from cheaper and readily available materials. Activated carbons with their high surface area, micro porous character and chemical nature of their surface have made them potential adsorbents for the removal of heavy metals from water.Caboxylic, lactonic, phenolic, and other organic functional groups are located at the edges of hexagonal layer planes and are responsible for surface reactivity of activated carbon. Ionization of these functional groups in solution is $\mathrm{pH}$ dependent and leads to a build up of a charged interface between the solid surface and the bulk of the solution ${ }^{6}$.

There are a quite large number of studies regarding the preparation of activated carbons from agriculture wastes, fruit stones, hard shell of fruit stones. bagasse, manure compost, oil palm waste, agriculture residue from sugarcane, saw dust, Rosa canina sp. Seeds, sewage sludge ${ }^{7}$.Most of activated carbons are prepared by a two- stage process carbonization followed by activation. The first step is to enrich the carbon content and to create an initial porosity and activation process helps in enhancing the pore structure. The activation can be carried by two different processes physical and chemical. Chemical activation has two important advantages as compared to physical activation. One is lower temperature in which the process is accomplished. The other is that the global yield to the chemical activation tends to be greater since burn off char is not required ${ }^{8}$.Among the numerous dehydrating agents, sulphuric acid in particular is the widely used chemical agent in the preparation of activated carbon.

Lapsi seed stone is the waste product of Lapsi fruits. (Lapsi) Choerospondias axillaris belongs to the family Anacardiaceous. It is a large, fruit bearing deciduous tree native to the hills of Nepal (865-1900m). Lapsi fruit is consumed fresh, pickled or processed into a variety of sweet and sour fruit products locally called "Mada" or"Titaura". It is a rich source of vitamin C. It is also believed to aid in digestion and is often consumed after a protein rich meal. Seed stones are used as fuel in brick kilns in the factories and the trunk of the tree is used as fuel wood and timber,10. Iron impregnated activated carbon prepared from Lapsi seed stone had been investigated for the removal of arsenic from water ${ }^{9}$. In this study, activated carbon developed from Lapsi seed stones have been used for the removal of $\mathrm{Pb}$ (II) ions from aqueous solution since the stones are readily available and can be used as a viable adsorbent for the removal of heavy metals. The effects of initial adsorbate concentration and $\mathrm{pH}$ on the removal of $\mathrm{Pb}$ (II) have been studied.

\section{Experimental}

\section{Preparation of Adsorbents}

Lapsi seeds were first washed with tap water then with distilled water and dried in an oven at $110^{\circ}$ $\mathrm{C}$ for 12 hours. The dried seeds were crushed into small particles by Jaw Crusher. The Lapsi seed particles were divided into two parts. One part of the Lapsi seed particles were treated with concentrated $\mathrm{H}_{2} \mathrm{SO}_{4}$ in 1:1 weight ratio and kept in an oven maintained at a temperature of $150{ }^{\circ} \mathrm{C}$ for 24 hours ${ }^{\mathbf{1 1}}$. The particles were then washed with distilled water till the $\mathrm{pH}$ and conductivity of the washing were equal to that of distilled water. The particles were dried in an oven at $110^{\circ} \mathrm{C}$ for 12 hours. The particles were then ground and sieved to get the particles size of $100 \mu \mathrm{m}$. The carbon has been named as Carbon -1.

Another part of the Lapsi seed particles were treated with concentrated $\mathrm{H}_{2} \mathrm{SO}_{4}$ in 1:1 weight ratio The mixture was then treated with conc. $\mathrm{HNO}_{3}$ for further oxidation and was kept in an oven at $150{ }^{\circ} \mathrm{C}$ for 24 hours. The dried mixture was washed with distilled water till the $\mathrm{pH}$ and conductivity of the washing were equal to that of distilled water. The acid free sample was dried, ground and then sieved to the particle size of $100 \mu \mathrm{m}$. The carbon has been named as Carbon-2.

\section{Characterization of the activated Carbon}

Characterization of the resultant adsorbent was studied by FTIR study and Boehm titration. The Fourier transform infrared (FTIR) spectra were recorded on a Perkin-Elmer Model 1605 FT-IR 
spectrometer. Oxygen containing functional groups present on the activated carbons prepared were determined qualitatively by the FTIR spectroscopy. Quantification of the functional groups was determined by Boehm titration.

\section{Chemicals}

All chemicals and reagents used were of analytical grade. Stock solutions of $\mathrm{Pb}$ (II) were prepared from lead nitrate in deionized water. Digital $\mathrm{pH}$ meter was used to measure the $\mathrm{pH}$ values of the solutions. Solutions of $0.1 \mathrm{M} \mathrm{NaOH}$ and $0.1 \mathrm{HNO}_{3}$ were used for $\mathrm{pH}$ adjustment. All the working solutions were prepared diluting the stock solutions with deionized water.

\section{Adsorption studies}

Batch adsorption experiments were carried out in a series of stoppered reagent bottles. A weighed amount $(0.05 \mathrm{~g})$ of adsorbent was introduced into the reagent bottles $(50 \mathrm{ml})$ containing various concentration of lead. The total volume of the aqueous solution is equal to $25 \mathrm{ml}$.The solution $\mathrm{pH}$ was adjusted to the desired value by adding $0.1 \mathrm{M} \mathrm{HNO}_{3}$ and $0.1 \mathrm{M} \mathrm{NaOH}$. The bottles were then shaken at room temperature $\left(25 \pm 2{ }^{0} \mathrm{C}\right)$ using an electric shaker for a prescribed time to attain the equilibrium. The solutions were filtered and final concentrations of lead (II) ions were determined by using an atomic absorption spectrophotometer with hallow cathode lamp and air acetylene flame. The instrument calibration was checked by using standard metal solutions. The amount of lead (II) ions adsorbed was calculated by the following mass balance equation.

$$
q_{\mathrm{e}}=\frac{\left(\mathrm{C}_{\mathrm{o}}-\mathrm{C}_{\mathrm{e}}\right) \mathrm{V}}{\mathrm{M}} \quad 1
$$

Where $\mathrm{C}_{\mathbf{0}}$ and $\mathrm{C}_{\mathbf{e}}$ were initial and equilibrium concentration of metal ion $(\mathrm{mg} / \mathrm{L})$ respectively, $\mathrm{m}$ was the mass of adsorbent in gram $(\mathrm{g})$ and $\mathrm{V}$ was the volume of the solution in liter $(\mathrm{L})$.

\section{Results and Discussion}

\section{FTIR}

FTIR study confirmed the presence of oxygenated functional groups in C-1 and C-2. The FTIR spectrum of the C-1 and C-2 is shown in Fig.1. The bands at about $1604 \mathrm{~cm}^{-1}$ and $1720 \mathrm{~cm}^{-1}$ are attributed to $v(\mathrm{C}-\mathrm{O})$ vibrations in the carboxyl groups. The bands at about $1300-1365 \mathrm{~cm}^{-1}$ are attributed to $v(\mathrm{O}-\mathrm{H})$ vibrations in the hydroxyl and phenolic groups. The appearance of bands between 900 and $1300 \mathrm{~cm}^{-1}$ could be assigned to $\mathrm{C}-\mathrm{O}$ stretching vibrations. It is obvious that the main oxygen groups present in the $\mathrm{C}-1$ and $\mathrm{C}-2$ are lactones, carboxyl and phenolic groups ${ }^{\mathbf{1 2}}$.

\section{Boehm Titration}

The quantification of surface oxygen functional groups in $\mathrm{C}-1$ and $\mathrm{C}-2$ was measured by Boehm titration method ${ }^{13},{ }^{14}$. The method based on that the weakest base $\mathrm{NaHCO}_{3}$ neutralizes only the strongest acidic carbon surface functionalities which are carboxyl groups, while $\mathrm{Na}_{2} \mathrm{CO}_{3}$ neutralizes carboxylic and lactonic groups. The strongest base $\mathrm{NaOH}$ neutralizes carboxylic, lactonic and phenolic groups. On the basis of amount of acid and bases consumed the different kinds of functional groups can be quantitatively calculated. Table-1 shows the mill equivalent of carboxylic, phenolic and lactonic groups present per gram of activated carbon. The large quantities of the acidic functional groups on the surface of $\mathrm{C}-1$ and $\mathrm{C}-2$ make them high cation exchange capacity and benefit for the $\mathrm{Pb}$ (II) ions adsorption ${ }^{\mathbf{1 5}}$. 
Table 1: Boehm titration result of Carbon -1 and Carbon -2

\begin{tabular}{|c|c|c|c|}
\hline Adsorbents & \multicolumn{3}{|c|}{ Functional groups in mill equivalent per gram (meq/g) } \\
\hline & Carboxyl & Phenol & Lactones \\
\hline Carbon-1 & 0.75 & 0.62 & 0.5 \\
\hline Carbon-2 & 1.25 & 0.75 & 0.6 \\
\hline
\end{tabular}

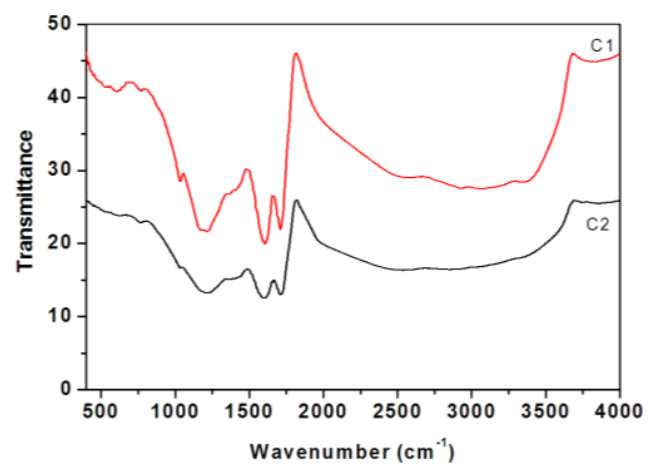

Fig.1. FTIR Study of Carbon-1 and Carbon-2

\section{Effect of $p H$}

The $\mathrm{pH}$ of the solution has a significant impact on the uptake of heavy metals since it determines the surface charge of the adsorbent, the degree of ionization and speciation of the adsorbate. The effect of $\mathrm{pH}$ on the adsorption of $\mathrm{Pb}$ (II) on activated carbons prepared from Lapsi seeds has been studied by varying $\mathrm{pH}$ from 2-6 as shown in Fig 2 and 3. It has been shown in the figure that the uptake of Pb depends on $\mathrm{pH}$, it increases with the increase in $\mathrm{pH}$ and reaching maximum adsorption of $\mathrm{Pb}$ around $\mathrm{pH} 5{ }^{16}$.The continued increase in adsorptive capacities of $\mathrm{Pb}$ with increase in $\mathrm{pH}$ is due to the decrease in hydrogen
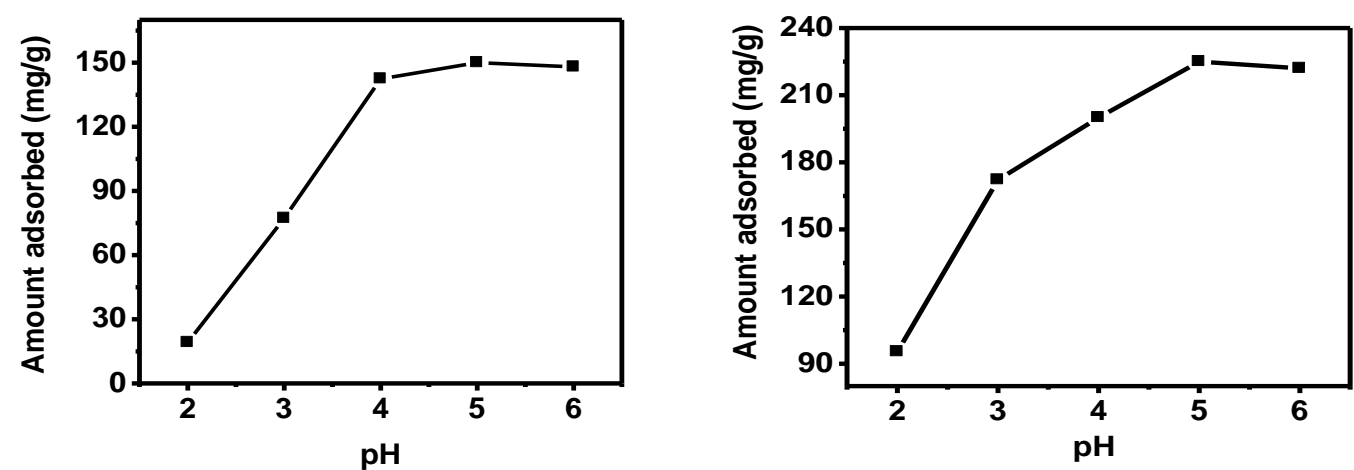

Fig.2. (left): Effect of $\mathrm{pH}$ on adsorption of $\mathrm{Pb}^{2+}$ on $\mathrm{C}$-1, Initial concentration=200 $\mathrm{mg} / \mathrm{L}$. Fig.3. (right): Effect of $\mathrm{pH}$ on adsorption of $\mathrm{Pb}(\mathrm{II})$ on $\mathrm{C}-2$, Initial concentration $=400 \mathrm{mg} / \mathrm{L}$ 
ion concentration as $\mathrm{pH}$ value increases. At lower $\mathrm{pH}$ higher concentration of $\mathrm{H}^{+}$ions present in aqueous medium will compete with the positively charged $\mathrm{M}^{2+}$ ion for the surface adsorbing sites thereby leading to a decrease in the removal of metal ions ${ }^{\mathbf{9 6}}$. In other words under acidic condition solutions both adsorbent and metal ions are positively charged $\left(\mathrm{M}^{2+}\right.$ and $\left.\mathrm{H}^{+}\right)$and hence their interaction is via electrostatic interaction. The final $\mathrm{pH}$ values at equilibrium after adsorption were lower than the initial $\mathrm{pH}$ value, indicating that the $\mathrm{Pb}$ ions are adsorbed and hydrogen ions are released from the adsorbent. This is also confirmed by the result that the increase of acidic surface groups favored the adsorption process. The effect of $\mathrm{pH}$ on $\mathrm{Pb}$ (II) adsorption onto two carbons was studied over a $\mathrm{pH}$ range $2-6$ at $25^{\circ} \mathrm{C}$ in order to avoid the formation of metal hydroxides.

\section{Effect of metal ion concentration}

In batch adsorption processes the initial metal ion concentration of metal ions in solution plays an important role as driving force to overcome the mass transfer resistance between the solution and solid phase. So the removal efficiency of $\mathrm{Pb}$ ions by activated carbon derived from Lapsi seed stones initially increased with increasing metal ion concentration as shown in Fig.4. At initial stage there were large number of binding sites available for adsorption i.e. the number of lead ions available in the solution is

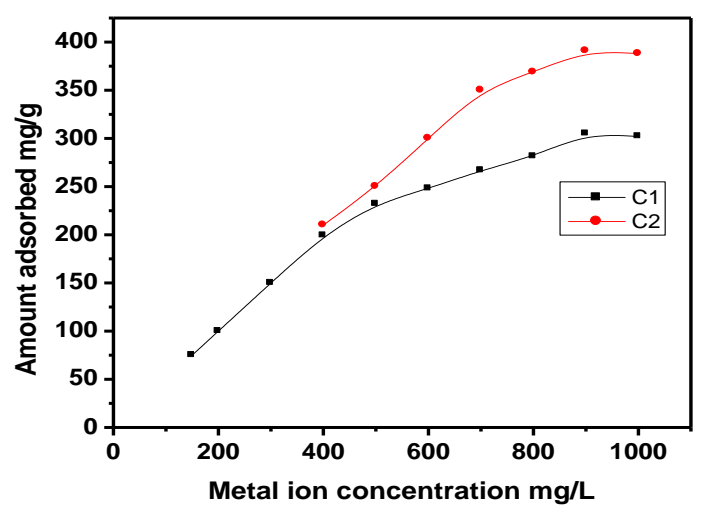

Fig.4. Effect of concentration of $\mathrm{Pb}(\mathrm{II})$ on adsorption at $\mathrm{pH} 5$

less as compared to the available sites on the adsorbents and the metal ions in solution would interact the binding sites and thus facilitate more adsorption whereas in higher concentrations the metal ions get left unabsorbed in the solution due to saturation of the binding sites ${ }^{17}$.

\section{Adsorption isotherm}

Adsorption isotherm indicates how molecules of adsorbate distribute between the solid and liquid phase when the adsorption process reaches an equilibrium state ${ }^{18}$. Several models have been used in the literature to describe the experimental data of adsorption isotherms. Langmuir and Freundlich models are most frequently employed models. In the present work both the models were used. The main assumption of the Langmuir adsorption isotherm is that adsorption occurs uniformly on the active part of the surface and when a molecule is adsorbed on an active site, the other molecules could not be interacted with this active site.

The linear form of Langmuir isotherm equation is given as

$$
\frac{C_{e}}{q_{e}}=\frac{1}{q_{m} b}+\frac{1}{q_{m}} C_{e}
$$


Where $\mathrm{q}_{\mathrm{e}}$ is the amount of lead ions adsorbed $(\mathrm{mg} / \mathrm{g}$ ) and Ce is the equilibrium concentration of lead ions in the bulk solution $\left(\mathrm{mg} / \mathrm{L}\right.$ ) while $\mathrm{q}_{\mathrm{m}}$ is the monolayer adsorption capacity $(\mathrm{mg} / \mathrm{g}$ ) and $\mathrm{b}$ is the Langmuir constant ${ }^{19}$. Langmuir constant and adsorption capacity are determined from the slope and intercept of the plot $\mathrm{Ce} / \mathrm{qe}$ versus $\mathrm{Ce}$ and are presented in Table-2.

Table - 2. Langmuir and Freundlich constants for lead adsorption onto C-1 and C-2 at pH 5

\begin{tabular}{|c|c|c|c|c|c|c|}
\hline Adsorbents & \multicolumn{3}{|c|}{ Langmuir } & \multicolumn{3}{c|}{ Freundlich } \\
\hline & $\mathrm{b}$ & $\mathrm{q} \mathbf{m}$ & $\mathrm{R}^{2}$ & Log $\mathrm{H}$ & $1 / \mathrm{n}$ & $\mathrm{R}^{2}$ \\
\hline Carbon-1 & 0.209 & 277.8 & 0.994 & 0.069 & 2.263 & 0.964 \\
\hline Carbon-2 & 0.339 & 423.7 & 0.998 & 0.050 & 2.489 & 0.823 \\
\hline
\end{tabular}
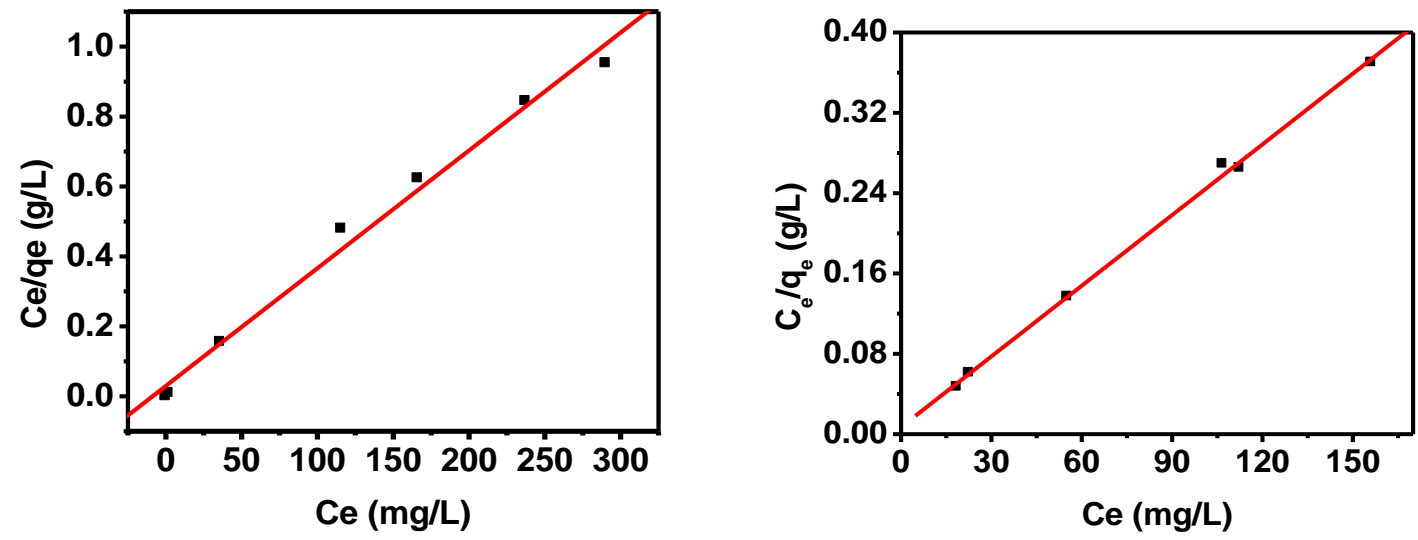

Fig.5(left): Langmuir isotherm of $P b(I I)$ on $C-1$ at $p H$ 5. Fig.6(right): Langmuir isotherm of $P b(I I)$ on C-2 at $\mathrm{pH} 5$

Freundlich isotherm is purely empirical and it best describes the adsorption on heterogeneous surfaces. Freundlich equation is shown below in its linear form:

$$
\log q_{e}=\log \mathrm{K}+\frac{1}{\mathrm{n}} \log \mathrm{C}_{\mathrm{e}}
$$

Where $\mathrm{K}$ and $\mathrm{n}$ areFreundlich constants related to adsorption capacity and adsorption intensity respectively. From the slope and intercept of straight portion of the linear plot obtained by plotting log qe versus $\log \mathrm{Ce}$, the values of Freundlich parameters are calculated ${ }^{\mathbf{2 0}}$.

Langmuir and Freundlich constants are given in Table-2. Fig. 5 and 6 show that the isotherm data better fits the Langmuir equation than Freundlich equation since the correlation coefficient values $\left(\mathrm{R}^{2}\right.$ $=0.994$ and 0.998 for $\mathrm{C}-1$ and $\mathrm{C}-2$ respectively) are higher than that in Freundlich isotherms $\left(\mathrm{R}^{2}=0.823\right.$ and 0.964). Langmuir and Freundlich constants are given in Table -2 . 

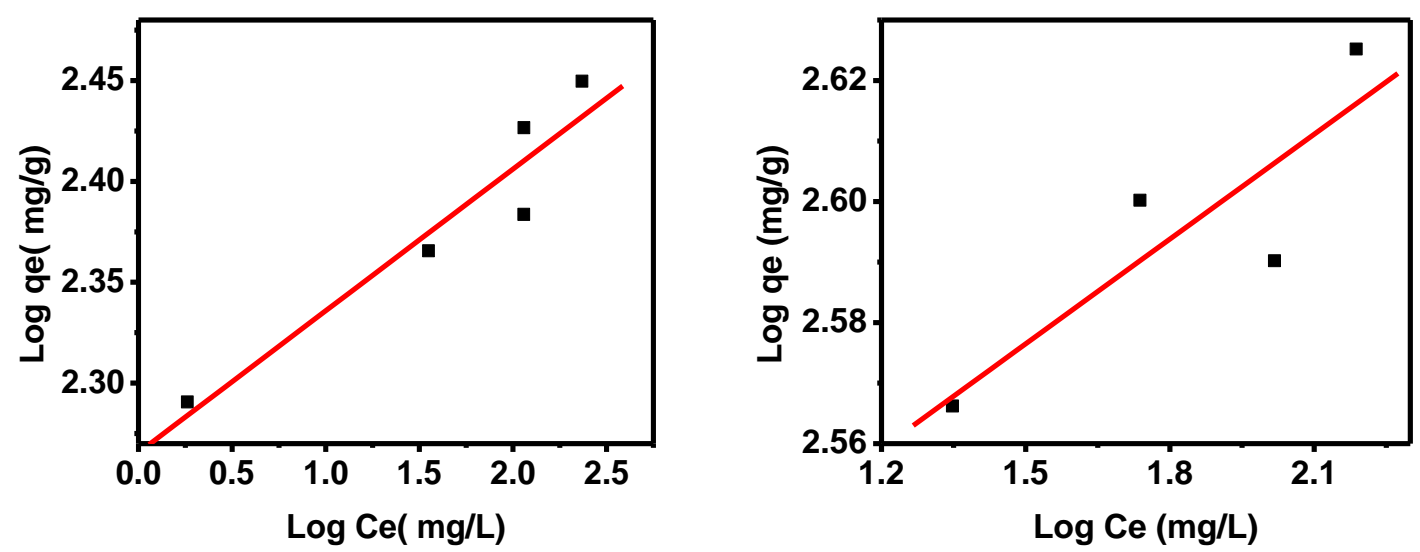

Fig. 7 (left): Freundlich isotherm of $P b(I I)$ on $C-1$ at pH 5. Fig. 8 (right): Freundlich isotherm of $P b(I I)$ on $\mathrm{C}$-2 at $\mathrm{pH} 5$

Carbon -2 shows more adsorptive power than C-1 since Carbon- 2 has more surface functional group than $\mathrm{C}$-1.The activated carbons prepared from Lapsi Seed Stone are better in adsorption of $\mathrm{Pb}$ (II) than the adsorbents prepared from Red mud, peat and biomass Enteromorpha prolifera. The activated carbons prepared are comparable with the activated carbons prepared from Modified orange peel and Fruit palm oil as shown in Table-3.

Table -3 Adsorption capacities of lead by various adsorbents

\begin{tabular}{|c|l|l|l|}
\hline S.No. & \multicolumn{1}{|c|}{ Adsorbents } & \multicolumn{1}{c|}{$\begin{array}{c}\text { Adsorption } \\
\text { capacity } \\
\mathbf{q m}_{\mathbf{m}} \mathbf{~ m ~ g}^{-1}\end{array}$} & \multicolumn{1}{c|}{ References } \\
\hline 1 & Red mud & 88.2 & Gupta et. al ,2001 \\
\hline 2 & Peat & 95.2 & Ho and Mckay,1999 \\
\hline 3 & $\begin{array}{l}\text { AC from Enteromorpha } \\
\text { prolifera }\end{array}$ & 146.85 & Yanhui Li et. al 2010 \\
\hline 4 & Modified orange peel & 476.1 & Ningchuan Feng et. al,2011 \\
\hline 5 & AC from fruit palm oil & 588.0 & Olubenga Solomon Bello,2010 \\
\hline 6 & Carbon -1 & 277.8 & This study \\
\hline 7 & Carbon-2 & 423.7 & This study \\
\hline
\end{tabular}

\section{Conclusion}

The present investigation showed that activated carbons derived from Lapsi seed stones are effective adsorbents for the removal of lead (II) from aqueous solutions. The amount adsorbed increased with the increase in $\mathrm{pH}$ from 2 to 5. Experimental results are in good agreement with Langmuir adsorption isotherm model, and have shown a better fitting to the experimental data. Boehm titration study showed that there is a large quantity of functional groups such as carboxyl, phenolic and lactonic groups existed on the surface of $\mathrm{C}-1$ and $\mathrm{C}-2$.Batch adsorption experiment showed that $\mathrm{Pb}$ (II) ion adsorption properties 
are great dependence on $\mathrm{pH}$ and metal ion concentration. The optimum $\mathrm{pH}$ for the uptake of lead adsorption on the adsorbents is 5. The carbon prepared by chemical activation with a mixture of $\mathrm{H}_{2} \mathrm{SO}_{4}$ and $\mathrm{HNO}_{3}$ showed more adsorptive capacity than that of the carbon prepared by treatment with $\mathrm{H}_{2} \mathrm{SO}_{4}$.

\section{Acknowledgement}

The authors are grateful to European Union for providing Erasmus Mundus Scholarship to carry out the research work at Eotvos Lorand University, Budapest, Hungary. Thanks also go to NAST (Nepal Academy of Science and Technology) for providing PhD fellowship to undertake the research work in home country, Nepal.

\section{References}

1. M.Mohammad, S.Maitra, N.Ahmad A.Bustam, T.K Sen. B.K. Dutta, J. Hazardous Materials, 2010, 170, 263.

2. H. Lalhruaitluanga, K. Jayaram, M.N.V. Prasad, K.K. Kumar, J. Hazardous Material,2010, 175 , 311.

3. T.K.Naiya, A.K.Bhattacharya, S.K.Das, J. Hazardous Materials, 2009, 170, 252.

4. O. Gercel, H.Ferdi Gercel, Chemical Engineering Journal 2007,132 189.

5. C.Karthika, N.Venilamani, S.Pattabhi, M.Sekar, International Journal of Engineering Science and Technology ,2010 Vol.2 (6)

6. M.Momcilovic.M.Purenovic. A. Bojic, A. Zarubica, M. Randolovic, Desalination, $2011276,53$.

7. S.Z. Mohammadi, M. A. Karimi, D. Afzali, F. Mansouri, Desalination, 2010, 263 , 83.

8. L.Mouni, D. Merabet,A Bouzaza, L.Belkhiri, Desalination, 2011, 276,148.

9. N. Lamsal, M.Sc. dissertation on Adsorption of of Cd (II) from aqueous by activated Charcoal Derived from Lapsi Seeds 2008, Central Dept. of Chemistry, Tribhuvan University,Kirtipur, Nepal.

10. R. Piya M.Sc. dissertation on Adsorption of Chromium (VI) by Low cost activated carbon prepared from waste seeds 2007, Central Department of Chemistry, Tribhuvan University, Kirtipur, Nepal

11. S.Gupta B.V.Babu, J. of Environmental Management, 2009, 90 , 3013.

12. K. Acharya, J.N. Sahu, B.K. Sahoo, C.R. Mohanty, B.C. Meikap, Chemical Engineering Journal , 2009, 149, 249.

13. S.L. Goertzen, Kim D. The'riault, Alicia M. Oickle Anthony C. Tarasuk Heather A. Andreas, Carbon, 2010, 48, 1252.

14. A. M. Oickle, Sarah L. Goertzen ,L. Goertzen, Katelyn R. Hopper Yasmin O. Abdalla, Heather A. Andreas, Carbon, 2010, 48, 3313.

15. H.M. Boehm, Carbon, 2002, 40, 145.

16. T. K. Naiyaa, A. K.Bhattacharya, S. Mandalb, S. K. Das, J. Hazardous Materials, 2009, 163, 1254.

17. F.Y. Wang, H.Wang. Jian W. Ma, J. Hazardous Materials, 2010, 177, 300.

18. K.Li, Z.Zheng, Ye, Li, J. Hazardous Materials, 2010, 181, 440.

19. Y.Li,Q,Du, X.Wang, P.Zhang, D.Wnag, Z.Wang, Y.Xia , J. Hazardous Materials, 2010,183, 583.

20. A.Chakravarty,A.Mohanty,T.N.Sudha,A.K.Upadhyaya,,J.Konar,J.K.Sirkar,A.Madhukar,K.K.Gu pta, J. Hazardous Materials, 2010, 173 , 502. 